\title{
O Papel de Representações Sociais sobre a Natureza da Homossexualidade na Oposição ao Casamento Civil e à Adoção por Famílias Homoafetivas
}

\author{
Cicero Roberto Pereira \\ Instituto de Ciências Sociais da Universidade de Lisboa \\ Ana Raquel Rosas Torres \\ Universidade Federal da Paraíba \\ Luciene Falcão \\ Universidade Paulista \\ Annelyse Soares Pereira \\ Instituto Universitário de Lisboa
}

\begin{abstract}
RESUMO - Analisaram-se as relações entre preconceito, apoio a políticas discriminatórias contra homossexuais e representações sociais sobre a natureza da homossexualidade. Participaram da pesquisa 297 estudantes do último ano de psicologia, serviço social e direito. Os resultados mostram que as representações sobre a homossexualidade baseadas em crenças religiosas, moralistas e psicológicas predizem o maior apoio às políticas discriminatórias contra os homossexuais, nomeadamente a oposição ao casamento e à adoção de crianças por casais homoafetivos. A crença na natureza cultural da homossexualidade prediz o menor apoio a essas políticas. As relações verificadas são mediadas pelo preconceito flagrante contra homossexuais. Esses resultados mostram o papel desempenhado por representações sobre a natureza dos grupos sociais na manutenção de preconceitos e práticas discriminatórias contra minorias sociais.
\end{abstract}

Palavras-chave: preconceito, discriminação, homofobia, crenças essencialistas, representações sociais

\section{The Role of Social Representations about the Nature of Homosexuality: Opposition to Civil Marriage and Adoption by Homoaffective Families}

\begin{abstract}
In this study the relationship between prejudice, support of discriminating policies against homosexuals and people's social representations about the nature of homosexuality was analyzed. Participants were 297 final year psychology, social work, and law students. Results showed that the representations about homosexuality based on religious, moralist, and psychological beliefs are positively related to the support of discriminating policies against homosexuals, specifically the opposition to civil union and to children's adoption by homosexuals. Beliefs about the cultural nature of homosexuality predicted lower support of these policies. These relations were mediated by blatant prejudice against homosexuals. These results show the role played by social representations about the nature of social groups in the maintenance of prejudices and discriminatory practices against minority groups.
\end{abstract}

Keywords: prejudice, discrimination, homophobia, essentialist beliefs, social representations

Dentre as diversas inovações inseridas no censo demográfico brasileiro realizado em 2010, uma das mais importantes é o levantamento do número de casais homossexuais existentes no Brasil. Os resultados apontam que existem mais de 60 mil casais homossexuais (IBGE, 2011). Essa informação é importante não apenas para traçar o retrato da população brasileira e assim fornecer bases para o desenvolvimento de políticas públicas, mas também porque a própria inclusão dessa variável no censo pode ser considerada um indicador de mudanças profundas que vêm ocorrendo na sociedade brasileira no que se refere à garantia dos direitos civis das minorias sexuais. Outro importante exemplo dessa mudança é a decisão, tomada em 5 de maio de 2012 pelo Supremo Tribunal Federal (STF), que considera a união homoafetiva como regime jurídico da união estável. O STF também legitimou essa união como entidade familiar, o que garante direitos formais aos

1 Endereço para correspondência: Avenida Professor Aníbal de Bettencourt, 9. 1600-189, Lisboa - Portugal. E-mail: cicero.pereira@ics.ul.pt casais homossexuais de todo o país no que tange à herança e à adoção. Por fim, ainda em maio de 2012, a comissão de juristas que discute a reforma do Código Penal no Senado aprovou a proposta que criminaliza o preconceito contra gays, transexuais e transgêneros. Embora o texto ainda não tenha sido submetido à aprovação pelo Congresso Nacional, representa um importante passo em direção ao combate à violência contra minorias sexuais.

Apesar da legitimação das relações homoafetivas pelo sistema jurídico brasileiro, a situação das minorias sexuais é crítica no Brasil. Como exemplo, uma pesquisa realizada por Castro, Abramovay e Silva (2004) em 14 capitais brasileiras, com estudantes do ensino médio e seus pais, mostrou que $25 \%$ dos participantes não gostariam de ter um homossexual como colega na mesma sala de aula. Exemplo mais dramático é o fato da homofobia ter sido a motivação de 250 casos de assassinatos em 2010, o que coloca o Brasil em primeiro lugar no ranking desse tipo de crime, ficando muito à frente do México, com 35 assassinatos, e dos EUA, com 25 (Grupo Gay da Bahia, 2011). 
Situação dramática também se verifica quando se coloca a possibilidade de adoção de crianças por famílias homoparentais (Zambrano, 2006). Apesar de existir ampla evidência empírica mostrando ausência de diferenças no desenvolvimento e na socialização de crianças educadas por famílias homoparentais ou por famílias heterossexuais (Bailey, Dobrow, Wolfe, \& Mikach 1995; Flaks, Ficher, \& Masterpasqua, 1995; Golombok \& Tasker 1996; Picazio, 1998), a rejeição a esse tipo de adoção ainda é forte. Exemplo dessa oposição pode ser encontrado no estudo realizado por Figueiredo (2003) sobre a adoção de crianças por homossexuais solteiros e por casais homossexuais, o qual mostrou que menos da metade dos participantes (incluindo juízes e desembargadores; promotores e procuradores de justiça; psicólogos e assistentes social; advogados; professores universitários e donas de casa) são favoráveis à adoção em favor do homossexual solteiro e que apenas 36,8\% eram favorável à adoção por casal homossexual. Esse estudo também mostrou que a opinião favorável ao indeferimento de um pedido de adoção em razão da opção sexual do solicitante foi menor nos psicólogos e assistentes sociais do que nos promotores e procuradores. Diante dessas evidências, associadas às notícias recentes veiculadas nos meios de comunicação sobre assassinatos de homossexuais ainda não oficialmente contabilizados, parece ser pertinente sugerir a possibilidade de existir no Brasil representações sociais (RS) normativas sobre a homossexualidade que, de certa forma, permitem a expressão de atitudes e comportamentos homofóbicos.

Especificamente, a questão investigada neste trabalho diz respeito às relações entre preconceito, apoio a políticas discriminatórias contra homossexuais e as RS sobre a natureza da homossexualidade. Esse questionamento é importante porque pouca atenção tem sido dada à análise do papel de RS mais específicas, como é o caso das teorias de senso comum sobre a natureza de grupos sociais, no preconceito e na discriminação. De fato, apesar do tema "homossexualidade" despertar cada vez mais o interesse do mundo acadêmico, como mostra um levantamento feito no Portal de Periódicos da Capes em 20 de maio de 2012 inserindo a palavra "homossexuality" como termo de busca, a análise da relação entre RS, preconceito e discriminação contra homossexuais ainda é rara. Isso pode ser visto no levantamento realizado que mostrou existirem 170 trabalhos publicados, dos quais apenas três utilizavam a Teoria das Representações Sociais como ferramenta de análise. Além disso, todos tratavam de pesquisas de levantamento sobre os conteúdos representacionais sobre diferentes aspectos da homossexualidade. A análise dos demais trabalhos identificados indicou que em 2001 foram publicados apenas quatro estudos. Dez anos depois, 24 artigos tratam do tema e, até maio de 2012, tinham sido publicados 73 trabalhos. No entanto, a análise desses trabalhos permite classificá-los em duas grandes categorias: estudos que abordam a identidade homossexual a partir de diferentes perspectivas psicanalíticas e estudos sobre como as minorias sexuais constroem uma identidade homossexual. Assim, nenhum dos trabalhos apresentou estudos sobre o papel das RS no preconceito e no apoio que as pessoas dão a políticas discriminatórias contra homossexuais.

Com o objetivo de contribuir para preencher essa lacuna, o presente artigo apresenta um estudo sobre o papel de RS sobre a natureza da homossexualidade na expressão de preconceito flagrante, na oposição ao casamento entre pessoas do mesmo sexo e à adoção de crianças por casais homossexuais. No Brasil, quando alguém decide adotar uma criança, primeiro ela deve ser entrevistada por um assistente social e depois por um psicólogo. Na última etapa, é um juiz, baseado nos laudos feitos por esses profissionais, quem decide se a pessoa poderá ou não adotar uma criança. Assim, o estudo que será apresentado considerou dois critérios de inclusão para selecionar os participantes deste estudo: a) deveriam ser graduandos de direito, serviço social ou psicologia e b) deveriam estar no último ano do curso, uma vez que já teriam, de certa forma, internalizado não só os conhecimentos teóricos das respectivas profissões, mas também os discursos sociais característicos de cada uma delas. A hipótese investigada é a de que as representações sobre a homossexualidade predizem o preconceito bem como o apoio às políticas discriminatórias. Essa hipótese assenta na ideia de que se essas representações são fatores importantes para o apoio que as pessoas dão a políticas discriminatórias contra homossexuais, as relações entre as crenças sobre a homossexualidade e a discriminação contra homossexuais devem ser mediadas pelo preconceito flagrante contra homossexuais. Para realizar o estudo aqui apresentado, utilizou-se como fundamento teórico o Modelo de Análise Quantitativa das Representações Sociais (Doise, Clémence, \& Lorenzi-Cioldi, 1993).

\section{Representações sobre a Natureza dos Grupos Sociais e Preconceito Contra os Homossexuais}

Os estudos sobre o essencialismo psicológico têm mostrado que as teorias implícitas que as pessoas mantêm sobre a natureza dos grupos sociais são fatores centrais para compreendermos as tensões intergrupais (Haslam, Bastian, \& Bissett, 2004; Leyens et al, 2000; Pereira, Vala, \& Leyens, 2009). De acordo com Allport (1954), as pessoas tendem a acreditar que tanto os objetos naturais como os fatos sociais possuem um conjunto fixo e imutável de atributos, ou essências, que definem a natureza desses objetos e fatos. Analisando esse princípio no processo de categorização, Rothbart e Taylor (1992) propuseram que, da mesma forma que as pessoas atribuem essências na descrição que fazem das categorias de objetos percebidos como naturais, elas também fazem isso para categorias sociais. Por exemplo, pessoas que são percebidas como um grupo ou uma categoria social (e.g., o que se acredita serem os grupos raciais) são representadas no senso comum como se fossem uma espécie biológica. O mecanismo subjacente ao pensamento essencialista é o de que as pessoas usam teorias que lhes permitem inferir uma suposta natureza profunda que supõem caracterizar objetos sociais a partir da mera observação de características arbitrárias que pensam serem descritoras desses objetos (Keller, 2005). O essencialismo é, portanto, uma teoria de senso comum baseada na crença de que cada categoria de objetos tem um conjunto fixo de características que definem a natureza de cada elemento da categoria (Medin \& Ortony, 1989). Quando as pessoas usam essa crença para descrever a natureza dos grupos sociais, o fazem, sobretudo, para 
justificar as desigualdades sociais e a discriminação contra grupos minoritários (Pereira, Vala, \& Costa-Lopes, 2010).

No que se refere à homossexualidade, Hegarty e Pratto (2001) identificaram duas dimensões ou dois tipos de crenças essencialistas (ver também, Haslam, Rothschild \& Ernst, 2002): a imutabilidade (a crença de que a homossexualidade tem uma base biológica, fixada no início da vida e difícil de mudar) e a diferença fundamental (a crença de que os homossexuais têm alguma natureza profundamente diferente das pessoas não homossexuais). Os autores constataram uma correlação negativa entre a crença na imutabilidade e o preconceito contra os homossexuais; e uma correlação positiva entre esse preconceito e a crença na diferença fundamental. Mais recentemente, Haslam e Levy (2006) identificaram uma terceira dimensão das crenças essencialistas sobre a homossexualidade: universalização (crenças de que a homossexualidade é cultural e historicamente variável). Esses autores também verificaram que as crenças na imutabilidade e na universalização se correlacionavam negativamente com o preconceito contra os homossexuais, no entanto a crença na diferença fundamental se relacionava positivamente.

A síntese dos estudos sobre as relações entre crenças essencialistas e preconceito contra os homossexuais sugere que teorias implícitas sobre os grupos sociais são fatores importantes para compreendermos o preconceito face aos homossexuais. Contudo, um aspecto que necessita ser realçado é a evidência da investigação realizada nesse domínio ter restringido o seu escopo ao papel do essencialismo biológico, dando pouca ou nenhuma atenção a um conjunto mais amplo de crenças que pode ser mais importante para fundamentar a discriminação contra os homossexuais. Exemplos desse conjunto de crenças são as teorias de senso comum baseadas na ideia de que a homossexualidade é resultante da fraqueza do indivíduo para resistir ao que se acredita serem tentações demoníacas, fraqueza moral e, no domínio da relação entre ciência e senso comum, na crença de que a homossexualidade seria um distúrbio psicológico (Pereira, Torres, Pereira, \& Falcão, 2011).

A análise mais completa sobre a importância das crenças sobre a natureza da homossexualidade deve considerar o essencialismo no âmbito dos processos descritos por Moscovici (1976) e por Doise (1986) na caracterização que fazem das teorias de senso comum sobre a realidade social (Moscovici \& Hewstone, 1983). De fato, a essencialização é um exemplo prototípico do que Moscovici descreveu como "objetivação", explicando como as pessoas naturalizam conceitos e relações científicas, transformando-as em conhecimento de senso comum. Desta forma, as crenças essencialistas sobre a homossexualidade são mais bem analisadas no contexto das RS sobre grupos sociais, na medida em que são princípios organizadores das crenças e explicações socialmente elaboradas sobre a natureza desses grupos (Pereira et al., 2011).

No caso do preconceito contra os homossexuais, o processo psicossocial subjacente a essa proposta baseia-se na hipótese de que as teorias e práticas científicas, quando transformadas em conhecimento de senso comum sobre a homossexualidade, são fontes de justificação para a discriminação contra os homossexuais (Camino, 1998). De fato, Lacerda, Pereira e Camino (2002) identificaram cinco princípios organizadores de um amplo conjunto de crenças sobre a homossexualidade: natureza religiosa (a crença de que a homossexualidade é uma profunda e imutável predisposição para o pecado e para a desobediência às leis de Deus); natureza ético-moral (a crença de que os homossexuais partilham uma profunda tendência para violar os valores tradicionais, incluindo o que se acredita ser o valor da decência, da moralidade e as boas maneiras); natureza psicológica (a crença de que os homossexuais têm profundos distúrbios psico-afetivos); natureza biológica (a crenças de que a homossexualidade tem base genética, fixa e imutável); natureza psicocultural (conjunto de crenças não-essencialistas assente na ideia de que a homossexualidade tem base cultural e representa uma expressão normal da sexualidade humana).

Lacerda et al. (2002) também constataram que o preconceito flagrante em relação aos homossexuais estava baseado na crença em uma suposta natureza ético-moral e religiosa da homossexualidade, enquanto o preconceito sutil estava mais relacionado com crenças na natureza biológica e psicológica. Apenas a crença na natureza cultural da homossexualidade estava relacionada com atitudes igualitárias face aos homossexuais. Com base nesses resultados, Lacerda et al (2002) concluíram que as RS sobre a natureza da homossexualidade podem contribuir para a manutenção de práticas sociais homofóbicas na medida em que essas crenças são amplamente difundidas no pensamento de senso comum e são usadas para legitimar as políticas e ações sociais direcionadas aos homossexuais.

Com base na revisão da literatura aqui apresentada propõe-se a hipótese de que a relação entre as RS sobre a homossexualidade e o apoio a políticas discriminatórias são mediadas pelo preconceito contra os homossexuais. $\mathrm{O}$ argumento para essa hipótese é o de que, se as representações estão na base do preconceito e da discriminação (Moscovici \& Pérez, 1997), é de se esperar que o preconceito funcione como um dos mecanismos por meio dos quais as representações levem os participantes a apoiarem as políticas discriminatórias contra os homossexuais, como, por exemplo, a oposição à união civil e à adoção de crianças por casais homossexuais. Especificamente, com base em pesquisas anteriores (Lacerda et al, 2002; Pereira et al., 2011), propõe-se que as representações sobre uma suposta natureza religiosa, moral, biológica e psicológica da homossexualidade devem prever maior preconceito contra os homossexuais e, consequentemente, maior preconceito deve implicar numa maior discriminação contra os homossexuais. O padrão oposto deve emergir com crenças na natureza cultural da homossexualidade. Especificamente, com base na teorização e nos resultados dos estudos discutidos até aqui, prevê-se que as representações religiosas, ético-morais, biológicas e psicológicas, e a menor adesão à crença na natureza cultural da homossexualidade devem implicar maior preconceito contra os homossexuais e, consequentemente, o maior nível de preconceito deve implicar maior apoio às políticas discriminatórias contra homossexuais. Adicionalmente, considerando que as atitudes em relação aos homossexuais são consistentemente relacionadas com as características demográficas dos indivíduos (Haslam \& Levy, 2006; Wilkinson \& Roys, 2005), as hipóteses foram testadas controlando os efeitos destas variáveis.

Na verdade, embora a literatura, neste domínio, ainda não tenha apresentado teoria sobre os efeitos de variáveis sócio- 
-demográficas no preconceito contra os homossexuais, ela tem mostrado que essas variáveis são importantes preditores do preconceito contra homossexuais. Portanto, é importante controlar o efeito dessas variáveis com o objetivo de evitar a análise e teorização sobre relações espúrias.

\section{Método}

\section{Participantes}

Participaram 297 estudantes concluintes dos cursos de psicologia $(n=100)$, serviço social $(n=97)$ e direito $(n=$ 100) em uma universidade situada na Região Centro-Oeste do Brasil. Todos os participantes indicaram ser heterossexuais. A idade dos participantes varia de 17 a 61 anos $(M=$ $26,22$ anos, $D P=8,42)$. A maioria $(80 \%)$ dos participantes é do sexo feminino, $68 \%$ são solteiros, $57 \%$ se identificaram como católicos, $18 \%$ como evangélicos, $12 \%$ espíritas e $12 \%$ afirmaram não possuir religião.

\section{Medidas $^{2}$}

Aplicou-se um questionário que, além de conter indicadores sobre as características sócio-demográficas dos participantes (sexo, idade, estado civil, tipo de curso e religião), continha uma medida de crenças sobre a natureza da homossexualidade, uma medida de preconceito contra homossexuais, uma medida de oposição à adoção de crianças por casais homossexuais, uma medida de oposição ao casamento entre pessoas do mesmo sexo ${ }^{3}$.

Representações sobre a natureza da homossexualidade: Usou-se a escala de crenças sobre a homossexualidade elaborada e validada por Lacerda et al. (2002). Essa escala é composta por 15 itens que mensuram cinco tipos de representações sobre a natureza da homossexualidade: religiosas; biológicas; ético-morais; psicológicas; culturais. A tarefa dos participantes foi indicar o seu grau de concordância com cada item da escala. As respostas podiam variar de 1 (discorda totalmente) a 7 (concorda totalmente). Submetemos os escores obtidos a uma análise fatorial (método dos eixos principais) fixando, a priori, o limite de cinco fatores a serem extraídos. Os cinco fato-

2 Realizou-se uma análise exploratória dos dados com o objetivo de averiguar em que medida a distribuição das respostas às variáveis atendem os requisitos mínimos para a análise paramétrica de dados. Seguindo os procedimentos comumente recomendados (Judd \& McClelland, 2001), verificou-se que a base de dados não contém casos extremos multivariados. Além disso, a inspeção feita aos valores de skewness e kurtosis indicou uma moderada assimetria na distribuição das representações religiosa e um ligeiro achatamento leptocúrtico nas representações ético-morais. Contudo, os pressupostos para a análise paramétrica estão assegurados na medida em que a análise dos resíduos mostrou que estes são homogêneos e normalmente distribuídos, apesar do uso de preditores de natureza categórica em análise de regressão e modelos de equações estruturais. $\mathrm{O}$ mesmo se verificou na análise dos resíduos dos itens usados nas diversas análises fatoriais a seguir apresentadas.

3 O questionário com todas as medidas aqui descritas está disponível para consulta e utilização mediante requisição direta aos autores. res obtidos explicam $57,24 \%$ da variância das respostas à escala e organizaram os itens conforme os cinco tipos de crenças previstos. O primeiro fator satura as crenças na natureza religiosa (cargas fatoriais variando de 0,63 a 0,70 ; autovalor $=1,99$; variância explicada $=13,27 \%$ ). O segundo fator organiza as crenças ético-morais (cargas fatoriais variando de 0,56 a 0,72 ; autovalor $=1,87$; variância explicada $=12,46 \%)$. No terceiro fator saturam as crenças psicológicas (cargas fatoriais variando de 0,52 a 0,87 ; autovalor $=1,77$; variância explicada $=11,79 \%$ ). No quarto fator saturam as crenças culturais (cargas fatoriais variando de 0,58 a 0,66 ; autovalor $=1,49$; variância explicada $=9,94 \%$ ). O quinto fator organiza as crenças biológicas (cargas fatoriais variando de 0,57 a 0,62 ; autovalor $=1,47$; variância explicada $=9,78 \%$ ). Em seguida, construímos cinco índices, um para cada tipo de crenças, os quais apresentam elevada consistência interna: religiosas $(\alpha=0,87)$; ético-morais $(\alpha=0,84)$; psicológicas $(\alpha=$ $0,73)$; culturais $(\alpha=0,69)$; e biológicas $(\alpha=0,72)$.

Preconceito. Aplicou-se a escala de rejeição a relações de proximidade com homossexuais desenvolvida e validada por Lacerda et al. (2002) para medir o preconceito contra homossexuais. Essa medida é uma adaptação da escala de rejeição à intimidade proposta por Pettigrew e Meertens (1995) para medir uma das principais dimensões do racismo flagrante. A tarefa dos participantes era indicar em que medida se sentiram constrangidos em relação a cada uma das situações descritas nesses itens. As respostas variam de 1 (nada constrangido) a 7 (muitíssimo constrangido). Calculou-se uma análise fatorial (método dos eixos principais) aos escores obtidos. Apenas um fator foi extraído (cargas fatoriais variando de 0,70 a 0,82; autovalor $=4,03$ ), que explica $57,59 \%$ da variabilidade nas respostas. Além disto, essa medida apresenta consistência interna muito elevada $(\alpha=0,90)$, permitindo-nos construir um índice de preconceito em que os escores mais elevados indicam maior preconceito contra os homossexuais.

Oposição à adoção de criança por homossexuais. Foi desenvolvida uma escala de oposição dos participantes à adoção de crianças por homossexuais. A escala contém 30 itens, sendo que metade descreve um posicionamento favorável (e.g., "Um casal de gays ou lésbicas bem ajustados têm mais condições de adotar uma criança"; "Casais homossexuais têm condições emocionais de oferecerem lares dignos para crianças") e metade descreve um posicionamento desfavorável a esse tipo de adoção (e.g., "É melhor que uma criança permaneça numa instituição aguardando um casal heterossexual do que ser adotada por homossexuais"; "Uma criança adotada por gays ou lésbicas poderá ser abusada sexualmente por eles"). A tarefa dos participantes era indicar o seu grau de concordância com cada item da escala. As respostas podiam variar de 1 (discorda totalmente) a 7 (concorda totalmente). Os escores obtidos foram submetidos a uma análise fatorial (método dos eixos principais), extraindo-se apenas um fator que explica $45 \%$ da variância nos escores (cargas fatoriais variando de $-0,74$ a 0,72 ; autovalor $=13,00)$. Após invertermos a direção das respostas com carga fatorial negativa, construímos um índice de oposição à adoção de crianças por homossexuais, o qual apresenta consistência interna muito elevada $(\alpha=0,95)$. Escores mais elevados indicam maior oposição a esse tipo de adoção. 
Oposição à união civil entre homossexuais. Elaborou-se também uma escala de oposição dos participantes à união civil entre homossexuais. A escala é composta por 23 itens, sendo 14 descrevendo posicionamentos favoráveis (e.g., "As pessoas devem ter o direito de escolher o sexo da pessoa com quem deseja se casar"; "Os políticos devem legalizar as leis do casamento homossexual) e 13 descrevendo posições contrárias (e.g., "O Brasil não deve legalizar a união homossexual"; "O casamento homossexual fere os valores da família tradicional") ao casamento entre pessoas do mesmo sexo. A tarefa dos participantes era indicar o seu grau de concordância com cada item da escala. As respostas podiam variar de 1 (discorda totalmente) a 7 (concorda totalmente). Os escores obtidos foram submetidos a uma análise fatorial (método dos eixos principais). Apenas um fator foi extraído, explicando $44 \%$ da variabilidade nos escores (cargas fatoriais variando de $-0,83$ a 0,76 ; autovalor $=10,00$ ). Após a inversão da direção das respostas com cargas fatoriais negativas, calculou-se um índice de oposição ao casamento homossexual. Essa medida tem consistência interna muito elevada $(\alpha=0,94)$. Escores mais elevados indicam maior oposição ao casamento homossexual.

\section{Procedimentos}

Os participantes responderam o questionário individualmente em aplicação coletiva em sala de aula. A coleta de dados foi conduzida por uma pesquisadora devidamente treinada e foi realizada antes da decisão do Supremo Tribunal Federal favorável à definição das uniões homoafetivas como família. A realização do estudo foi aprovada pelo comitê de ética em pesquisa e os participantes assinavam o termo de consentimento livre e esclarecido antes de responderem ao questionário.

\section{Resultados}

No primeiro passo analisaram-se as relações entre as representações sobre a natureza da homossexualidade e o preconceito contra os homossexuais, controlando o efeito das variáveis sócio-demográficas. Duas equações de regressão por bloco de variáveis foram calculadas. Na primeira equação, regrediu-se o preconceito no bloco das variáveis sócio-demográficas. Na segunda equação, acrescentou-se à equação anterior o bloco das representações sobre a homossexualidade. Os resultados mostram que o coeficiente de regressão múltipla, obtido na primeira equação, é significativamente diferente de zero, $R=0,40, F(9,281)=6,09$, $p<0,001$. Como pode ser constatada na Tabela 1 , apenas a idade e a pertença religiosa dos participantes predizem o preconceito contra os homossexuais: quanto maior é a idade, menor é o preconceito; os participantes de religião evangélica apresentam maior nível de preconceito do que os participantes sem religião. Na segunda equação de regressão, o coeficiente de regressão múltipla também é diferente de zero, $R=0,65, F(14,276)=14,62, p<0,001$. Além disso, o incremento na explicação da variância do preconceito pelas representações da homossexualidade é significativo, $F_{\text {Change }}$ $(5,276)=25,24, p<0,001$. Portanto, as representações
Tabela 1. Coeficientes de regressão padronizados (betas) obtidos na análise dos preditores do preconceito contra os homossexuais

\begin{tabular}{|c|c|c|}
\hline \multirow{2}{*}{$\begin{array}{l}\text { Preditores } \\
\text { Modelo 1: Sócio-Demográficas }\end{array}$} & \multicolumn{2}{|c|}{ Preconceito } \\
\hline & $\beta_{\text {Modelo 1 }}$ & $\beta_{\text {Modelo } 2}$ \\
\hline Sexo & $\left(0,14^{*}\right)$ & 0,10 \\
\hline Idade & $\left(-0,23^{* *}\right)$ & $-0,20 * * *$ \\
\hline Estado Civil: Solteiros & $(0,01)$ & 0,11 \\
\hline Casados & $(0,13)$ & 0,12 \\
\hline Religião: Espírita & $(-0,09)$ & 0,02 \\
\hline Católica & $(0,04)$ & $0,14^{*}$ \\
\hline Evangélica & $\left(0,21^{* *}\right)$ & 0,10 \\
\hline Curso: Direito & $(0,10)$ & 0,05 \\
\hline Psicologia & $(-0,06)$ & $-0,05$ \\
\hline$R_{\text {Ajustado }}^{2}$ & 0,14 & \\
\hline \multicolumn{3}{|l|}{ Modelo 2: Crenças (Adicionadas) } \\
\hline Ético-morais & & $0,14 \dagger$ \\
\hline Religiosas & & $0,22 * *$ \\
\hline Psicológicas & & $0,21 * * *$ \\
\hline Biológicas & & $-0,03$ \\
\hline Culturais & & $-0,19 * * *$ \\
\hline$R_{\text {Incremento }}^{2}$ & & 0,26 \\
\hline$R_{\text {Ajustado }}^{2}$ & & 0,40 \\
\hline
\end{tabular}

Nota. Na variável sexo atribuímos os seguintes valores: $0=$ feminino, 1 = masculino. A idade varia de 17 aos 61 anos. São variáveis dummy: o estado civil (grupo de referência $=$ outros); religião (grupo de referência $=$ participantes sem religião); curso (grupo de referência $=$ estudantes de serviço social). Os betas entre parênteses foram obtidos no primeiro passo (apenas o bloco de variáveis sócio-demográficas). $\dagger p<0,07,{ }^{*} p<0,05$, $* * p<0,01, * * * p<0,001$.

sobre a natureza da homossexualidade predizem significativamente o preconceito para além dos efeitos das variáveis sócio-demográficas.

Quando as representações são consideradas no modelo (ver novamente a Tabela 1), o efeito da idade continua a ser significativo, o efeito da pertença dos participantes à religião evangélica deixa de ser significativo, enquanto o efeito da pertença à religião católica passa a ser positivo e significativo: os estudantes católicos expressam maior nível de preconceito contra os homossexuais do que os estudantes sem religião após os efeitos das representações e das outras variáveis posicionais terem sido controlados. $\mathrm{O}$ efeito das crenças ético-morais é apenas marginalmente significativo ( $t$ 
$=1,83, p=0,07$ ), de modo que a maior adesão a esse tipo de crença implica maior preconceito contra os homossexuais. Os efeitos das crenças religiosas e psicológicas são positivos e significativos: a maior adesão a essas crenças implica maior nível de preconceito. Em contrapartida, o efeito das crenças culturais é negativo e significativo, de modo que a maior adesão a essas crenças implica menor nível de preconceito. $\mathrm{O}$ efeito das crenças biológicas não é significativo.

\section{Representações da Homossexualidade, Preconceito e Discriminação dos Homossexuais}

Tabela 2. Coeficientes de regressão padronizados (betas) obtidos na análise dos preditores dos indicadores de discriminação contra os homossexuais

\begin{tabular}{|c|c|c|c|c|c|c|}
\hline \multirow[b]{2}{*}{ Preditores } & \multicolumn{6}{|c|}{ Indicadores de Discriminação } \\
\hline & \multicolumn{3}{|c|}{ Oposição à Adoção } & \multicolumn{3}{|c|}{ Oposição ao Casamento } \\
\hline \multicolumn{7}{|c|}{ Modelo 1: Sócio-Demográficas } \\
\hline Sexo & $(0,07)$ & {$[-0,01]$} & $-0,05$ & $\left(0,16^{* *}\right)$ & {$[0,09]$} & 0,06 \\
\hline Idade & $(-0,11)$ & {$[-0,08]$} & 0,01 & $(-0,10)$ & {$[-0,05]$} & 0,01 \\
\hline Estado Civil: Solteiros & $(-0,22 *)$ & {$[-0,08]$} & $-0,13$ & $(-0,10)$ & {$[0,02]$} & $-0,01$ \\
\hline Casados & $(-0,02)$ & {$[-0,04]$} & $-0,08$ & $(0,06)$ & {$[0,02]$} & $-0,01$ \\
\hline Religião: Espírita & $\left(-0,17^{*}\right)$ & {$[-0,03]$} & $-0,04$ & $(-0,12)$ & {$[0,01]$} & 0,01 \\
\hline Católica & $(-0,02)$ & {$[0,12]$} & 0,06 & $(0,08)$ & {$[0,20 * *]$} & $0,16^{* *}$ \\
\hline Evangélica & $(0,22 * *)$ & {$[0,09]$} & 0,04 & $(0,39 * * *)$ & {$[0,25 * * *]$} & $0,22 * * *$ \\
\hline Curso: Direito & $(0,07)$ & {$[0,02]$} & $-0,01$ & $(-0,03)$ & {$[-0,09]$} & $-0,10$ \\
\hline Psicologia & $(0,04)$ & {$[0,08]$} & 0,10 & $(-0,04)$ & {$[-0,01]$} & 0,01 \\
\hline$R_{\text {Ajustado }}^{2}$ & 0,10 & & & 0,18 & & \\
\hline \multicolumn{7}{|c|}{ Modelo 2: Crenças (Adicionadas) } \\
\hline Ético-morais & & {$[0,27 * * *]$} & $0,21^{* * *}$ & & {$[0,20 * *]$} & $0,16^{* *}$ \\
\hline Religiosas & & {$[0,24 * * *]$} & $0,15^{* *}$ & & {$[0,28 * * *]$} & $0,21 * * *$ \\
\hline Psicológicas & & {$[0,17 * *]$} & 0,08 & & {$\left[0,15^{* *}\right]$} & 0,09 \\
\hline Biológicas & & {$[-0,01]$} & 0,01 & & {$[-0,07]$} & $-0,06$ \\
\hline Culturais & & {$[-0,25 * * *]$} & $-0,17 * * *$ & & {$[-0,28 * * *]$} & $-0,22 * * *$ \\
\hline$R_{\text {Incremento }}^{2}$ & & 0,43 & & & 0,37 & \\
\hline$R_{\text {Ajustado }}^{2}$ & & 0,54 & & & 0,55 & \\
\hline \multicolumn{7}{|c|}{ Modelo 3: Preconceito (Adicionado) } \\
\hline Preconceito & & & $0,41 * * *$ & & & $0,31 * * *$ \\
\hline$R_{\text {Incremento }}^{2}$ & & & 0,10 & & & 0,06 \\
\hline$R_{\text {Ajustado }}^{2}$ & & & 0,64 & & & 0,61 \\
\hline
\end{tabular}

Nota. Na variável sexo atribuímos os seguintes valores: 0 = feminino, 1 = masculino. A idade varia de 17 aos 61 anos. São variáveis dummy: o estado civil (grupo de referência $=$ outros); religião (grupo de referência $=$ participantes sem religião); curso (grupo de referência = estudantes de serviço social). Os betas entre parênteses foram obtidos no primeiro passo (apenas o bloco de variáveis sócio-demográficas). Os betas entre colchetes foram obtidos no segundo passo (bloco de variáveis sócio-demográficas + bloco das explicações da homossexualidade). ${ }^{*} p<0,05, * * p<0,01, * * *<0,001$. 
No segundo passo, analisaram-se as relações entre as representações da homossexualidade, o preconceito e a orientação para discriminação dos homossexuais, i.e., o suporte a políticas discriminatórias contra os homossexuais. Operacionalizou-se esta orientação como a oposição à adoção de crianças por casais homossexuais e oposição ao casamento entre pessoas do mesmo sexo. Novamente, controlou-se o efeito das variáveis sócio-demográficas. Neste passo, para cada indicador de discriminação, três equações de regressão foram calculadas.

Oposição à adoção. Os resultados da primeira equação $[R=0,36, F(9,281)=4,73, p<0,001]$ indicam que os participantes evangélicos se opõem à adoção de crianças por homossexuais mais do que os participantes que não têm religião, enquanto que os estudantes espíritas são mais favoráveis à adoção do que os sem religião (ver a Tabela 2). Os estudantes solteiros tendem a se opor menos a essa adoção. Na segunda equação $[R=0,75, F(14,276)=24,84$, $\left.p<0,001, F_{\text {Change }}(5,276)=53,14, p<0,001\right]$, quando as representações da homossexualidade são acrescentadas, o coeficiente de regressão também é diferente de zero, os efeitos do tipo de religião e do estado civil (solteiros) deixam de ser significativos. Como esperado, os efeitos das crenças ético-morais, religiosas e psicológicas são positivos e significativamente maiores do que zero: maior adesão a esses tipos de crenças implicam maior oposição à adoção de crianças por casais homossexuais. Também como previsto, o efeito das crenças na natureza cultural da homossexualidade é negativo e significativo, de modo que a maior adesão a esse tipo de crença está associada à menor oposição à adoção.

Na terceira equação $[R=0,81, F(15,275)=34,90, p<$ $\left.0,001, F_{\text {Change }}(1,275)=78,33, p<0,001\right]$, os efeitos das variáveis sócio-demográficas continuam a não ser significativos. O efeito das crenças psicológicas deixa de ser significativo. A magnitude dos efeitos das crenças ético-morais, religiosas e culturais diminui consideravelmente, mas continua significativa. Finalmente, como previsto, o efeito do preconceito é substancial e significativo, de modo que maior nível de preconceito implica maior oposição à adoção.

Oposição ao casamento. Os resultados da primeira equação $[R=0,45, F(9,281)=7,89, p<0,001]$ revelam que os participantes evangélicos e os estudantes do sexo masculino se opõem mais fortemente ao casamento homossexual (Tabela 2). Na segunda equação $[R=0,76$, $F(14,276)=26,43, p<0,001, F_{\text {Change }}(5,276)=47,95, p<$ $0,001]$, o efeito do tipo de religiâo (evangélica) continua a predizer significativamente essa oposição. Além disso, a pertença à religião católica passa a ser significativo. De maior importância teórica são os efeitos das representações da homossexualidade: a maior adesão às crenças ético-morais, religiosas e psicológicas implica maior oposição ao casamento homossexual; a maior adesão às crenças culturais está associada à menor oposição à adoção.

Na terceira equação $[R=0,79, F(15,275)=30,77, p$ $\left.<0,001, F_{\text {Change }}(1,275)=39,66, p<0,001\right]$, os efeitos das pertenças à religião católica e evangélica são significativos e indicam que estas predizem a oposição ao casamento homossexual mesmo após termos controlado os efeitos das representações da homossexualidade e do preconceito. Novamente, o efeito das crenças psicológicas deixa de ser significativo, enquanto que o tamanho dos efeitos das crenças ético-morais, religiosas e culturais diminui, mas continua significativo. Por fim, o efeito do preconceito é substancial e significativo, de modo que o maior nível de preconceito implica maior oposição a esse tipo de casamento.

\section{Análise das Mediações}

Para testar a hipótese de que a relação entre as representações sobre a natureza da homossexualidade e o apoio às políticas discriminatórias contra os homossexuais é mediada pelo preconceito, estimou-se um conjunto de regressões múltiplas hierárquicas por blocos de variáveis. Para a realização dessas análises, calculou-se um índice de discriminação a partir dos indicadores de oposição à adoção e ao casamento homossexual. A correlação entre esses dois indicadores é muito forte $(r=0,76, p<0,001)$, com elevada consistência interna quando agregados num índice $(\alpha=0,86)$. Como nas análises anteriores, os efeitos das variáveis sócio-demográficas foram controlados. Em seguida, três equações de regressão foram calculadas de modo a corresponder aos passos necessários para a estimação de efeitos mediados (Baron \& Kenny, 1986). No primeiro passo, analisaram-se os efeitos das representações da homossexualidade na discriminação. No segundo passo, analisaram-se os efeitos dessas representações no preconceito.

Os resultados podem ser visualizados na Figura 1. No primeiro passo $\left[R=0,79, R_{\text {Ajustado }}^{2}=0,61, F(14,276)\right.$ $=33,69, p<0,001]$, os efeitos das crenças ético-morais, religiosas e psicológicas são positivos e significativos, de modo que a maior adesão a essas crenças implica maior suporte à discriminação. Em contrapartida, o efeito das crenças culturais é negativo e significativo: a maior adesão a essas crenças está associada ao menor suporte à discriminação. As crenças biológicas não predizem esse suporte. No segundo passo, verificou-se esse mesmo padrão de resultados: relações positivas das crenças ético-morais, religiosas e psicológicas com o preconceito; uma relação negativa entre a adesão às crenças culturais e o preconceito; efeito não significativo das crenças biológicas (os resultados desse segundo passo foram apresentados mais detalhadamente na descrição dos resultados da Tabela 1). No terceiro passo $\left[R=0,85, R_{\text {Ajustado }}^{2}=0,70, F(15,275)\right.$ $=45,71, p<0,001]$, quando o preconceito é acrescentado ao modelo, o preconceito mostrou-se ser o principal preditor do suporte às políticas discriminatórias. Além disso, o efeito das representações sobre a natureza da homossexualidade diminui. Esses resultados indicam que o preconceito medeia parcialmente as relações entre estas representações e o suporte às políticas discriminatórias contra os homossexuais. Os resultados do teste de Sobel mostram que os efeitos mediados são significativos, $Z_{\text {Ético- }}$ -morais $=1,80, p<0,05$ (unicaudal); $\mathrm{Z}_{\text {Religiosas }}=2,77, \stackrel{p}{<}<$ 0,$01 ; Z_{\text {psicológicas }}=3,19, p<0,001 ; Z_{\text {Culturais }}=3,13, p<0,001$. 


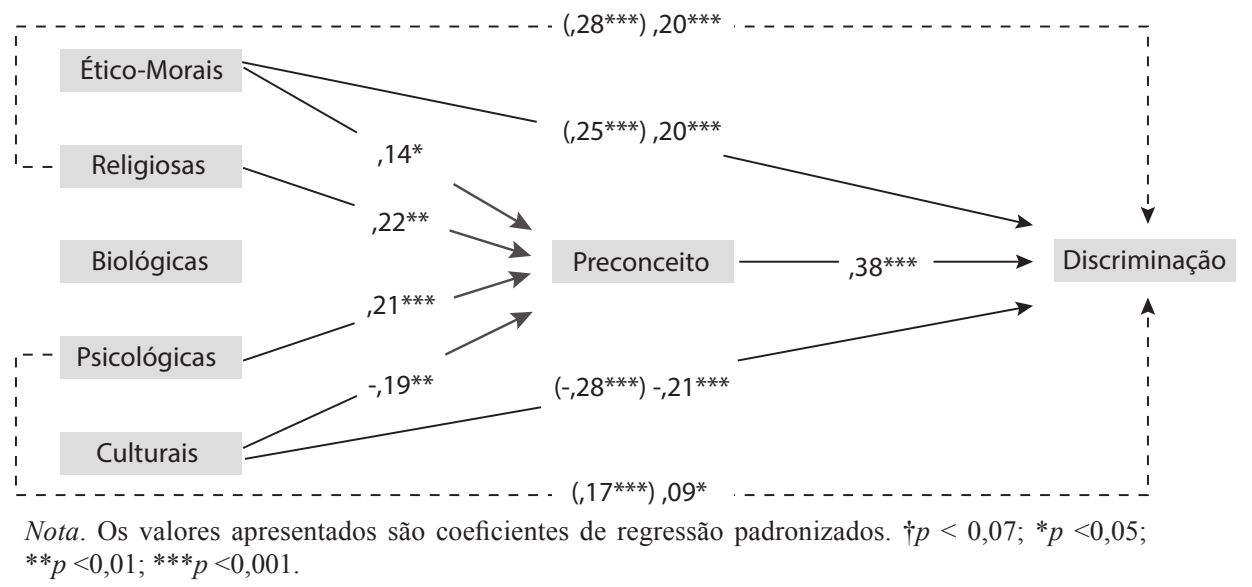

Figura 1. Coeficientes de regressão padronizados obtidos na análise das relações entre as representações sociais da homossexualidade e a discriminação contra os homossexuais, mediadas pelo preconceito.

\section{Análises complementares: Adequação do modelo}

Realizaram-se análises complementares objetivando testar a adequação do modelo aos dados observados. Usou-se a modelagem por equações estruturais com variáveis latentes. Os parâmetros foram estimados com base na matriz de variância-covariância dos indicadores, obtida por meio do procedimento de exclusão pairwise para dados ausentes. Estimou-se o modelo hipotetizado e comparou-se a sua adequação com dois modelos alternativos.

No modelo hipotetizado, especificaram-se sete variáveis latentes conceituais (i.e., os cinco tipos de crenças sobre a homossexualidade, o preconceito e a discriminação). Objetivando garantir a identificação estatística dos modelos, as cargas fatoriais de um dos indicadores de cada variável latente foram fixadas em 1,00. Especificaram-se os cinco tipos de crenças de modo que fosse possível se correlacionarem livremente. Essas crenças foram inseridas como preditoras do preconceito e da discriminação. O preconceito foi especificado como uma variável mediadora entre as crenças e a discriminação. Os índices de adequação para o modelo hipotetizado mostram uma adequação muito boa (ver Tabela 3). A adequação desse modelo foi comparada com a adequação do primeiro modelo alternativo, no qual o preconceito foi especificado como uma variável preditora dos cinco tipos de crenças que, por sua vez, eram preditores da discriminação (Modelo Alternativo 1) e com o segundo modelo alternativo, no qual a discriminação era antecedente do preconceito, que era o preditor das cinco crenças (Modelo Alternativo 2). A adequação dos dois modelos alternativos não foi tão boa quanto a do modelo hipotetizado. De fato, o modelo proposto se adequa melhor aos dados do que o Modelo Alternativo $1, \Delta \chi^{2}(10, N=297)$ $=307,44, p<0,001$ e do que o Modelo Alternativo 2, $\Delta \chi^{2}$ $(15, N=297)=3210,03, p<0,001$.

\section{Discussão}

Analisaram-se as relações entre as RS da homossexualidade, o preconceito e a discriminação contra os homossexuais. A síntese dos resultados obtidos mostra que os princípios organizadores dessas representações se relacionam com o apoio a políticas homofóbicas e que as relações verificadas são mediadas pelo preconceito flagrante contra os homossexuais. Especificamente, mostrou-se que as representações sobre a natureza da homossexualidade baseadas em conceitos religiosos (e.g., profunda e imutável predisposição para pecar), ético-morais (e.g., tendência para o ataque aos valores que sustem o status quo) e psicológicas (e.g., profundos distúrbios psico-afetivos) estão positivamente relacionadas com o apoio à manutenção de políticas discriminatórias, i.e., a oposição à união civil e à adoção de crianças por casais homossexuais. Por outro lado, a representação da homossexualidade que recorre a fatores culturais (i.e., a crença de que a homossexualidade tem base cultural e é uma expressão normal da sexualidade humana) implica menor orientação para a discriminação. Nenhum efeito foi verificado envolvendo as representações que recorrem a fatores biológicos.

De maior importância teórica é o fato de as relações observadas terem sido mediadas pelo preconceito e a comparação entre os modelos ter mostrado que é empiricamente mais consistente conceber o preconceito como uma consequência do que como um preditor das crenças sobre a natureza da homossexualidade, ou como consequência da discriminação. Esses resultados indicam que o preconceito pode ser o mecanismo psicológico por meio do qual as RS sobre a natureza dos grupos sociais fomentam a discriminação contra esses grupos. Esses resultados podem ser compreendidos à luz da teoria das RS, principalmente devido ao fato de as representações resultarem da transformação de conceitos e relações elaborados no âmbito institucional e transformados em saber de senso comum (Moscovici \& Hewstone, 1983). Como Camino (1998) argumentou, o conhecimento elaborado e institucionalizado no domínio científico pode contribuir de forma decisiva para a formação de crenças e teorias de senso comum que guiam as relações que as pessoas e grupos sociais mantêm entre si. Este processo de transformação pode ser entendido à luz do conceito de princípios organizadores proposto por Doise (1986) para descrever de forma mais precisa o conceito de RS, i.e., o conhecimento institucionalizado parece ter organizado o posicionamento dos participantes face à homossexualidade e isso se mostrou ser decisivo para a expressão de preconceito e para o apoio que deram a políticas discriminatórias contra homossexuais. 
Tabela 3. Indicadores da adequação do modelo hipotetizado e dos modelos alternativos aos dados observados

\begin{tabular}{lccccccc}
\hline Modelos & $\chi^{2}$ & CFI & GFI & AGFI & RMSEA & & $\Delta \chi^{2}$ \\
\cline { 1 - 4 } Modelo Hipotetizado $(\mathrm{gl}=149)$ & 308,65 & 0,95 & 0,91 & 0,87 & 0,06 & & \\
Modelo Alternativo 1 $(\mathrm{gl}=159)$ & 616,09 & 0,86 & 0,81 & 0,75 & 0,10 & & 307,44 \\
Modelo Alternativo 2 $(\mathrm{gl}=164)$ & 629,68 & 0,86 & 0,82 & 0,76 & 0,09 & & 321,03
\end{tabular}

Nota. $\mathrm{gl}=$ graus de liberdade; $\mathrm{CFI}=$ Comparative Fit Index $; \mathrm{GFI}=$ Goodness-of-Fit Index $; \mathrm{AGFI}=$ Adjusted Goodness-Q $\mathrm{f}$-Fit Index $;$ RMSEA = Root Mean Square Error of Approximation. O $\Delta \chi^{2}$ compara cada modelo alternativo ao modelo hipotetizado. Todos os valores de $\chi^{2}$ são significativos com $p<0,001$.

As relações entre as crenças na natureza religiosa e ético-moral da homossexualidade com o preconceito e com a discriminação contra os homossexuais confirmam os resultados de investigações prévias, mostrando que crenças nesta natureza estão na base das atitudes anti-gays (Lacerda et al., 2002) e outras minorias sexuais, como a atitude anti-prostitutas (Pereira, Torres, \& Pereira, 2004). O efeito das crenças religiosas também é coerente com um conjunto de pesquisas que mostram o papel fundamental das crenças religiosas nas atitudes anti-homossexuais (Pereira et al., 2011; Wilkinson \& Roys, 2005). O efeito das crenças psicológicas também é coerente com os resultados prévios (Lacerda et al., 2002; Pereira et al., 2011), confirmando a ideia de que, mesmo as explicações baseadas em modelos teóricos desenvolvidos no domínio científico, quando transformadas em saber de senso comum, podem contribuir com os processos de exclusão social. As relações negativas entre a crença na natureza cultural também são coerentes com os resultados de investigações neste domínio (Camino \& Pereira, 2000; Lacerda et al., 2002), como as relações negativas verificadas por Haslam e Levy (2006) entre a crença de que a homossexualidade é histórica e culturalmente construída e as atitudes anti-gay.

A ausência de relação significativa das crenças na natureza biológica com o preconceito e a discriminação é o único resultado verificado que não apresenta coerência com a investigação sobre as crenças biológicas e genéticas e a atitude anti-gay (Haslam \& Levy, 2006; Jayaratne et al., 2006). De fato, no estudo realizado por Lacerda et al. (2002), essas crenças se relacionaram negativamente com o preconceito flagrante, mas ancoraram o preconceito sutil (Pereira et al., 2011). Também nas investigações feitas por Haslam e Levy (2006), constatou-se que as crenças essencialistas de base biológica se relacionaram negativamente com a atitude anti-gay, o mesmo ocorrendo nas investigações realizada por Jayaratne et al. (2006) sobre o papel das crenças no modelo genético nessas atitudes. Nesse sentido, em determinados contextos, as representações biológicas podem suscitar atitudes positivas em relação aos homossexuais, enquanto noutros, não apresentarem qualquer relação. Não se tem, por agora, evidência empírica sobre em quais contextos isso ocorre nem sobre os processos psicológicos neles envolvidos. $O$ fato é que o presente estudo é o primeiro em que se analisa a associação entre as crenças biológicas, o preconceito e a discriminação, controlando outros fatores importantes como as variáveis sócio-demográficas e, principalmente, as outras crenças sobre a homossexualidade. Os estudos anteriores não levaram em conta esses fatores.

Recorreu-se também à abordagem proposta por Doise et al. (1993) sobre os princípios organizadores e os interpreta- mos como as teorias de senso comum que captam os diversos significados que a homossexualidade tem adquirido na História, fundamentalmente a caracterização de sua natureza pelas instituições produtoras de padrões normativos de ações e reguladoras das relações sociais. Nesse sentido, é possível que as explicações para a natureza da homossexualidade produzidas no âmbito das instituições religiosas e científicas tenham sido absorvidas pela sociedade e transformadas em teorias de senso comum, as quais constituem os princípios organizadores das representações sobre a natureza da homossexualidade. Essas representações exprimem a crença, desenvolvida e difundida no âmbito da tradição judaico-cristã, de que o comportamento homossexual representa a fraqueza espiritual do indivíduo para resistir às tentações demoníacas, descumprindo o que se julga ser vontade de Deus e o distanciamento do modelo de família definido nessa tradição (Greenberg \& Bystryn, 1982). No entanto, essa visão da homossexualidade coocorre com outras concepções, desenvolvidas no contexto da produção do conhecimento científico, como é exemplo a difusão promovida pelas ciências médicas da crença de que a homossexualidade seria uma doença relacionada com fatores genéticos (Bullough, 1974; Haider-Markel \& Joslyn, 2008; Keller, 2005). Outro exemplo de difusão de crenças sobre a homossexualidade pode ser encontrado nos primeiros textos psicanalíticos sobre o tema que descrevem a homossexualidade como uma inversão no desenvolvimento sexual normal (Freud, 1905/1962).

As explicações biológicas e psicológicas exprimem a transformação dessas concepções em saber de senso comum. Um exemplo mais recente de explicações para a homossexualidade emerge no contexto dos primeiros movimentos gays e que, posteriormente, foram institucionalizadas pela American Psychological Association (1975). Essas explicações estão baseadas na evidência de que os comportamentos homoafetivos não estão relacionados a disfunções psicológicas e podem ser melhor compreendidos quando analisados no quadro mais geral das diversas possibilidades de expressão da orientação sexual (Camino \& Pereira, 2000; Conselho Federal de Psicologia, 1999). De fato, essa visão cultural da homossexualidade, embora ainda pouco difundida, vinculou-se, nas últimas décadas, a um conjunto de movimentos sociais que lutam pela universalidade dos direitos humanos, pela formalização de normas anti-preconceito e pela implementação de mecanismos que promovam uma maior inclusão social. Esse movimento foi motivado pela emergente importância do valor da igualdade como princípio organizador das relações sociais. A sua institucionalização foi patrocinada pela Organização das Nações Unidas e estiveram envolvidos intelectuais, políticos e cientistas inconformados com a falta de base científica que 
sustentasse várias formas extremas de exclusão social, como são exemplos, o racismo e o anti-semitismo. No caso da homossexualidade, a força da norma anti-preconceito, associada à ideia da orientação sexual ser cultural e socialmente construída, parece ser a base de atitudes menos preconceituosas e do apoio às políticas antidiscriminatórias contra os homossexuais (ver Pereira et al., 2011).

Embora a investigação aqui apresentada ofereça evidência empírica suficientemente forte para a sustentação das hipóteses postuladas, o estudo realizado não está isento de limitações. Além de ter sido realizado com uma amostra de estudantes universitários, outra limitação importante no presente estudo é o fato de ter pressuposto que tanto o preconceito como o apoio às políticas discriminatórias (i.e., oposição ao casamento e a adoção de crianças por casais homossexuais) estão ancorados nas representações. Nesse sentido, foi proposto um modelo de análise que parte das RS para a discriminação. Dada a natureza correlacional do estudo, não se pode afirmar que o processo ocorre neste sentido ou no sentido inverso, ainda que a comparação realizada entre o modelo hipotetizado e explicações alternativas tenha sustentado as hipóteses aqui propostas. Novas pesquisas tornando experimentalmente salientes as representações sobre a natureza da homossexualidade e observando o seu impacto no preconceito e na discriminação poderão identificar de forma mais precisa a fiabilidade da direção das relações propostas. Mesmo assim, a direção das relações propostas está teoricamente consistente com a ideia de as representações estarem na base das atitudes e dos comportamentos dos atores sociais (Moscovici, 1976), pois modelam o contexto e justificam as atitudes e comportamentos. Em conclusão, o estudo realizado mostrou que um tipo específico de RS (i.e., as crenças sobre a natureza da homossexualidade), analisadas no contexto das relações intergrupais, pode ser um fator preponderante na determinação das tensões entre os grupos, nomeadamente o preconceito e a discriminação. Assim, o desenvolvimento e aplicação de políticas públicas com o objetivo de reduzir o preconceito e promover a inclusão social dos homossexuais devem ter em conta o papel das concepções e teorias de senso comum sobre a natureza da homossexualidade, procurando combater as que promovem preconceito e valorizar as que promovem abertura e inclusão social, como é exemplo a crença na natureza cultural da homossexualidade.

\section{Referências}

Allport, G. W. (1954). The nature of prejudice. Reading: AddisonWesley.

American Psychological Association. (1975). Minutes of the council of representatives. American Psychologist, 30, 620-651.

Baron, R. M., \& Kenny, D. A. (1986). The moderator-mediator variable distinction in social psychological research: Conceptual, strategic, and statistical considerations. Journal of Personality and Social Psychology, 51, 1173-1182.

Bailey, J. M., Dobrow, D., Wolfe, M., \& Mikach, S. (1995). Sexual orientation of adult son of gays fathers. Developmental Psychology, 31, 124-129.

Bullough, V. (1974). Homosexuality and the medical model. Journal of Homosexuality, 1, 99-110.
Camino, L. (1998). Direitos humanos e psicologia. In Comissão de Direitos Humanos do Conselho Federal de Psicologia (Ed.), Psicologia, ética e direitos humanos (pp. 39-63). Brasília: Conselho Federal de Psicologia.

Camino, L., \& Pereira, C. (2000). O papel da Psicologia na construção dos direitos humanos: Análise das teorias e práticas psicológicas na discriminação ao homossexualismo. Perfil, 13, 49-69.

Castro, M. G., Abramovay, M., \& Silva, L. B. (2004). Juventudes e sexualidade. Brasília: Unesco.

Conselho Federal de Psicologia. (1999). Resolução número 1/1999: Normas de atuação para os psicólogos em relação à questão da orientação sexual. Brasília: Conselho Federal de Psicologia.

Doise, W. (1986). Les represésentations sociales: Définition d'un concept. In W. Doise \& A. Palmonari (Eds.), L'étude des représentations sociales (pp. 81-94). Paris: Delachaux.

Doise, W., Clémence, A., \& Lorenzi-Cioldi, F. (1993). The quantitative analysis of social representations. Hempel Hempstead: Harvester Wheatsheaf.

Figueiredo, B. C. L. (2003). Adoção para Homossexuais. Curitiba: Editora Juruá.

Flaks, D., Ficher F., \& Masterpasqua, F. J. G. (1995). Lesbian Choosing Motherhood: A comparative study of Lesbian and heterosexual parents and a their children. Developmental Psychology, 31, 105-114.

Freud, S. (1905/1962). Three Essays on the Theory of Sexuality Translation. In J. Strachey (Ed.), The standard edition of the complete psychological works of Sigmund Freud (Vol. 7, pp. 136-244). Londres: Hogarth.

Golombok, S., \& Tasker, F. (1996). Do parents influence the sexual orientation of their children? Findings from a longitudinal study of lesbian familiars. Developmental Psychology, 32, 03-11.

Greenberg, D. F., \& Bystryn, M. (1982). Christian intolerance of homosexuality. American Journal of Sociology, 88, 515-548.

Grupo Gay da Bahia (2011). Relatório 2010 sobre homofobia no Brasil. Retrieved March 30, 2011 from www.ggb.com.br.

Haslam, N., Bastian, B., \& Bissett, M. (2004). Essentialist beliefs about personality and their implications. Personality and Social Psychology Bulletin, 30, 1661-1673.

Haider-Markel, D. P., \& Joslyn, M. R. (2008). Beliefs About the Origins of Homosexuality and Support for Gay Rights: An Empirical Test of Attribution Theory. Public Opinion Quarterly, 72, 291-310.

Haslam, N., \& Levy, S. R. (2006). Essentialist beliefs about homosexuality: Structure and implications for prejudice. Personality and Social Psychology Bulletin, 32, 471-485.

Haslam, N., Rothschild, L., \& Ernst, D. (2002). Are essentialist beliefs associated with prejudice? British Journal of Social Psychology, 41, 87-100.

Hegarty, P., \& Pratto, F. (2001). Sexual orientation beliefs: Their relationship to antigay attitudes and biological determinist arguments. Journal of Homosexuality, 41, 121-135.

IBGE (2011). Censo Demográfico 2010. Rio de Janeiro: Instituto Brasileiro de Geografia e Estatística.

Jayaratne, T. E., Ybarra, O., Sheldon, J. P., Brown, T. N., Feldbaum, M., ... Pett, E. M. (2006). White Americans' genetic lay theories of race differences and sexual orientation: their relationship with prejudice toward blacks, and gay men and lesbians. Group Processes \& Intergroup Relations, 9, 77-94. 
Judd, C. M., \& McClelland, G. H. (2001). Data analysis: A model-comparison approach. Belmont: Wadsworth $\backslash$ Thomson Learning.

Keller, J. (2005). In genes we trust: The biological component of psychological essentialism and its relationship to mechanisms of motivated social cognition. Journal of Personality and Social Psychology, 88, 686-702.

Lacerda, M., Pereira, C., \& Camino, L. (2002). Um estudo sobre as formas de preconceito contra homossexuais na perspectiva das representações sociais. Psicologia: Reflexão e Crítica, 15, 165-178.

Leyens, J.-P., Paladino, P., Rodriguez-Torres, R., Vaes, J., Demoulin, S., Rodriguez-Perez, A., \& Gaunt, R. (2000). The emotional side of prejudice: The attribution of secondary emotions to ingroups and outgroups. Personality and Social Psychology Review, 4, 186-197.

Medin, D., \& Ortony, A. (1989). Psychological essentialism. In S. Vosniadou \& A. Ortony (Eds.), Similarity and analogical reasoning (pp. 179-195). New York: Cambridge Academic Press.

Moscovici, S. (1976). La psychanalyse, son image et son public. Paris: PUF.

Moscovici, S., \& Hewstone, M. (1983). Social representations and social explanations: From the "naive" to the "amateur" scientist. In M. Hewstone (Ed.), Attribution Theory: Social and Functional Extensions (pp. 98-125). Oxford: Blackwell.

Moscovici, S., \& Pérez, J. A. (1997). Prejudice and social representations. Papers on Social Representations, 6, 27-36.

Pereira, C., Torres, A. R. R., \& Pereira, A. (2004). Preconceito contra prostitutas e representações sociais da prostituição em estudantes de teologia católicos e evangélicos. In M. E. Lima, \& M. E. Pereira (Eds.), Estereótipos, preconceito e discriminação: Perspectivas teóricas e metodológicas (pp. 209-234). Salvador: EDUFBA.
Pereira, C., Torres, A. R. R., Pereira, A., \& Falcão, L. (2011). Preconceito contra homossexuais e representações sociais da homossexualidade em seminaristas católicos e evangélicos. Psicologia: Teoria e Pesquisa, 27, 73-82.

Pereira, C., Vala, J., \& Costa-Lopes, R. (2010). From prejudice to discrimination: The legitimizing role of perceived threat in discrimination against immigrants. European Journal of Social Psychology, 40, 1231-1250.

Pereira, C., Vala, J., \& Leyens, J.-P. (2009). From infrahumanization to discrimination: The mediation of symbolic threat needs egalitarian norms. Journal of Experimental Social Psychology, 45, 336-344.

Pettigrew, T. F., \& Meertens, R. W. (1995). Subtle and blatant prejudice in Western Europe. European Journal of Social Psychology, 25, 57-75.

Picazio, C. (1998) Diferentes desejos: Adolescentes homo, bi e heterossexuais. São Paulo: Summus.

Rothbart, M., \& Taylor, M. (1992). Category labels and social reality: Do we view social categories as natural kinds? In G. Semin \& K. Fiedler (Eds.), Language, interaction and social cognition (pp. 11-36). Newbury Park: Sage.

Wilkinson, W. W., \& Roys, A. C. (2005). The components of sexual orientation, religiosity, and heterosexuals' impressions of gay men and lesbians. Journal of Social Psychology, 145, 65-83.

Zambrano, E. (2006). Parentalidades “impensáveis": Pais/ mães homossexuais, travestis e transexuais. Horizontes Antropológicos, 12, 123-147.

Recebido em 23.09.2011

Primeira decisão editorial em 18.05.2012

Versão final em 29.01.2013

Aceito em 19.02.2013 